13. Deanfield JE, Shea MJ, Wilson RA, Horlock $P$, de Landsheere CM, Selwyn AP. Direct effects of smoking on the heart: silent ischemic disturbances of coronary flow. Am J Cardiol 1986;57:1005-1009.

14. Kannel WB, D'Agostino RB, Belanger AJ. Fibrinogen, cigarette smoking, and risk of cardiovascular disease: insight from the Framingham Study, Am Heart J 1987;113:1006-1010.

15. Meade TW, Imeson J, Stirling Y. Effects of changes in smoking and other characteristics on clotting factors and the risk of ischaemic heart disease. Lancet 1987;11:986-988.

16. Nowak J, Murray JJ, Oates JA, FitzGerald GA. Biochemical evidence of a chronic abnormality in platclet and vascular function in healthy individuals who smoke cigarettes. Circulation 1987;76:6-14.

17. Winniford MD. Smoking and cardiovascular function. J Hypertens 1990;8(suppl
5):S17 \$23.

18. Mancia G. Epidemiology, pathophysiology, and prevention of smoking. J Hyper tens 1990;8 (suppl 5):S57-S59.

19. Falk $\mathrm{E}$. The pathology of unstable angina and myocardial infarction. In: Chamberlain DA, Julian DG, Sleight P, eds. The Management of Acute Myocardial Ischaemia. London: Chapman and Hall Medical, 1990:1-9.

20. Fuster $\mathrm{V}$, Ip JH, Chesebro JH. Plaque disruption and thrombosis in acute ischaemic syndromes. In: Chamberlain DA, Julian DG, Sleight P, eds. The Management of Acute Myocardial Ischaemia. London: Chapman and Hall Medical, 1990:12-23.

21. Lau J, Antman EM, Jimenes-Silva J, Kupelnick B, Mosteller F, Chalmets TC. Cumulative meta-analysis of therapeutic trials for myocardial infarction. $N$ Engl $J$ Med 1992;327:248-254.

\title{
Histologic Characteristics of Tissue Excised During Directional Coronary Atherectomy in Stable and Unstable Angina Pectoris
}

Javier Escaned, MD, Robert J. van Suylen, MD, Donald C. MacLeod, MB, ChB, MRCP, Victor A. W. M. Umans, MD, Marcel de Jong, BEng, Fred T. Bosman, MD, PhD, Pim J. de Feyter, MD, PhD, and Patrick W. Serruys, MD, PhD

$\mathbf{U}^{\prime}$ nstable angina is an acute coronary syndrome associated with substantial short- and medium-term morbidity and mortality. ${ }^{1}$ The understanding of the pathogenesis of this syndrome has been based largely on postmortem studies of coronary arteries ${ }^{2}$ and supported by indirect evidence of coronary thrombosis in relation to the syndrome..$^{3-5}$ Because directional coronary atherectomy is unique in extracting intact atheromatous tissue during coronary recanalization, it may facilitate the study of the processes taking place in the vessel in different coronary syndromes. In the present study the histopathologic characteristics of atherectomy samples retrieved in 93 patients with stable or unstable angina pectoris were compared and related to different clinical variables.

We studied 93 patients who underwent directional coronary atherectomy providing histologic material at the Thoraxcenter during the period from 1989 to 1992. After the coronary atherectomy protocol was approved by the Thoraxcenter Institutional Review Board, informed consent was obtained in all patients before intervention. Directional coronary atherectomy was performed using the femoral approach. An average of $6 \pm 3$ passes in multiple directions were performed across the stenosis.

Clinical variables recorded included age, sex, previous myocardial infarction, current stable or unstable angina pectoris, previous coronary intervention and risk factors for coronary artery disease (history of hypercholesterolemia, non-insulin-dependent diabetes mellitus, cigarette smoking, hypertension and coronary artery disease in the family). Primary unstable angina was defined as continuous or intermittent chest pain at rest requiring hospitalization, associated with electrocardiographic evidence of myocardial ischemia but without associated increase in cardiac enzymes. The time inter-

From the Catheterization Laboratory, Thoraxcenter, and the Department of Pathology, Erasmus University, Postbus 1738, 3000 DR Rotterdam, the Netherlands. Dr. Escaned is supported by the FPU programme of the Spanish Ministry of Science and Education. Dr. MacLeod is a recipient of the British Heart Foundation International Research Fellowship. Mr. de Jong is a grant recipient from the Dutch Heart Foundation. Manuscript received September 23, 1992; revised manuscript received January 4, 1993, and accepted Janiary 5. val between the onset of chest pain and the atherectomy procedure was $7 \pm 5$ days.

The obtained specimens were fixed in 10\% formalin. Routine processing for light microscopy and hematoxylin-azophloxin and Verhoeff-van Giesson staining was performed. All specimens were reviewed by 2 independent observers who were unaware of the clinical data. The recommendations in the American Heart Association Medical/Scientific Statement on the definition of the intima of human arteries and of its atherosclerosis-prone regions ${ }^{6}$ were followed in collecting information regarding intimal constituents. Medial tissue was identified on the basis of parallel arrangement of smooth muscle cells, embedded in collagen and frequently associated with a fragment of the internal or external elastic lamina. Adventitia was recognized by the presence of coarse bundles of dense collagen inter-

\begin{tabular}{|c|c|c|c|}
\hline & Stable & Unstable & p Value \\
\hline \multicolumn{4}{|c|}{ Clinical Variables } \\
\hline Age (years, mean $\pm S D$ ) & $57.89 \pm 10.38$ & $56.84 \pm 10.85$ & NS \\
\hline $\begin{array}{l}\text { Previous myocardial } \\
\text { infarction }\end{array}$ & $13 / 48(27 \%)$ & $21 / 45(47 \%)$ & 0.05 \\
\hline Male sex & $39 / 48(81 \%)$ & $37 / 45(82 \%)$ & NS \\
\hline $\begin{array}{l}\text { Serum cholesterol } \\
\quad \geq 8 \mathrm{mmol} / \mathrm{L}\end{array}$ & $3 / 48(6 \%)$ & $3 / 45(7 \%)$ & NS \\
\hline Diabetes mellitus & $1 / 48(2 \%)$ & -- & \\
\hline Systemic hypertension & $12 / 48(25 \%)$ & $10 / 45(22 \%)$ & NS \\
\hline Cigarette smoking & $18 / 48(37 \%)$ & $16 / 45(36 \%)$ & NS \\
\hline $\begin{array}{l}\text { Family history of coro- } \\
\text { nary disease }\end{array}$ & $6 / 48(12 \%)$ & $9 / 45(20 \%)$ & NS \\
\hline $\begin{array}{l}\text { Previous coronary inter- } \\
\text { vention }\end{array}$ & $13 / 48(27 \%)$ & $11 / 45(24 \%)$ & NS \\
\hline Angina class (NYHA) & $\|: 22\| 11: 26$, & III:3, IV:42 & \\
\hline \multicolumn{4}{|c|}{ Histologic Variables } \\
\hline Dense fibrous tissue & $40 / 48(83 \%)$ & $39 / 45(86 \%)$ & NS \\
\hline Loose fibrous tissue & $12 / 48(25 \%)$ & $5 / 45(11 \%)$ & NS \\
\hline Neointimal hyperplasia & $14 / 48(29 \%)$ & $17 / 45(38 \%)$ & NS \\
\hline Cholesterol clefts & $4 / 48(8 \%)$ & $4 / 45(9 \%)$ & NS \\
\hline Necrotic debris & $3 / 48(6 \%)$ & $6 / 45(13 \%)$ & NS \\
\hline Calcium deposits & $9 / 48(19 \%)$ & $18 / 45(40 \%)$ & 0.042 \\
\hline Thrombus & $1 / 48(2 \%)$ & $10 / 45(22 \%)$ & 0.007 \\
\hline Macrophages & $6 / 48(12 \%)$ & $9 / 45(20 \%)$ & NS \\
\hline
\end{tabular}


mingled with elastin fibers, sometimes in association with fragments of the external elastic lamina and media. Fibrous tissue was classified as dense when composed of acellular or poorly cellular connective tissue formed predominantly by äeise collagen, ana ciassified as loose when the tissue fragments showed a moderate cellularity and collagen bundles separated by accumulations of extracellular matrix. Neointimal hyperplasia was defined as fibromuscular connective tissue showing a random orientation of spindle-shaped and stellate cells embedded in abundant extracellular matrix. Cholesterol crystal clefts, necrotic debris and calcium deposits were recorded independently. No special staining was used to identify calcium. The presence of macrophages was recorded only when these formed clusters or when they were present in unusually high number. Thrombus and intraplaque hemorrhage were identified as amorphous material, in close apposition with atheromatous material, frequently showing collecions of leukocyles beiween layers of fibrin. Areas consisting mainly of fibrin and not clearly related to the plaque that could have formed during the procedure
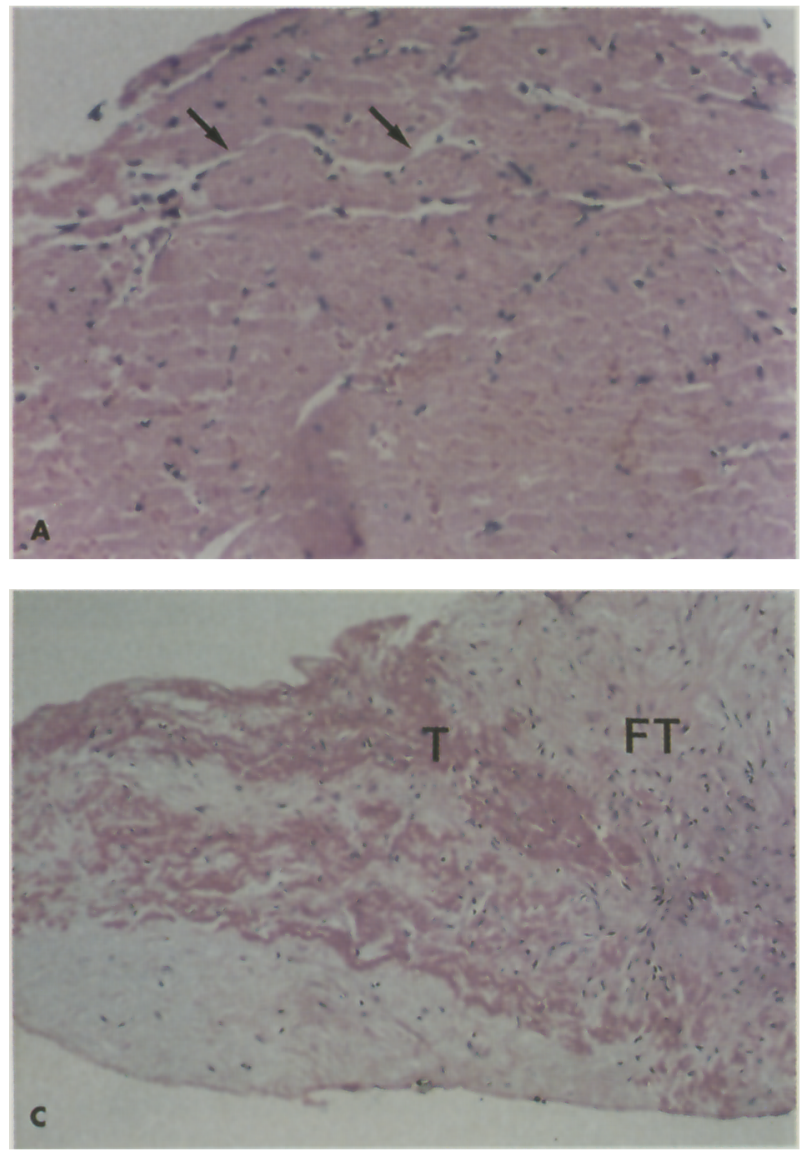

were not recorded. The Verhoef-van Giesson staining was used to discriminate between fibrin and dense collagen. Organization was judged when infiltration by cellular elements, e.g., smooth muscle cells. fibrohlasts and capillary sprouts, was observed, and graded from I to III on the basis of the number and characteristics of infiltrating cellular elements.

In the 43 patients with unstable angina, lesion morphology was classified according to the criteria proposed by Ambrose et al ${ }^{7}$ by 2 independent cardiologists unaware of the result of the histopathologic studies. Complex lesion morphology was recorded when eccentric lesions with overhanging or ragged edges, or lesions with multiple irregularies were noted. In case of disagreement, the opinion of a third cardiologist was taken into account.

Mean values $\pm S D$ are presented for continuous variables. Comparison of mean values was performed using 2-tailed unpaired $\mathbf{t}$ tests. Discrete variables were compared using chi-square tests, and Yates' continuity correction was applied when indicated. Statistical significance was accepted at the $5 \%$ level.
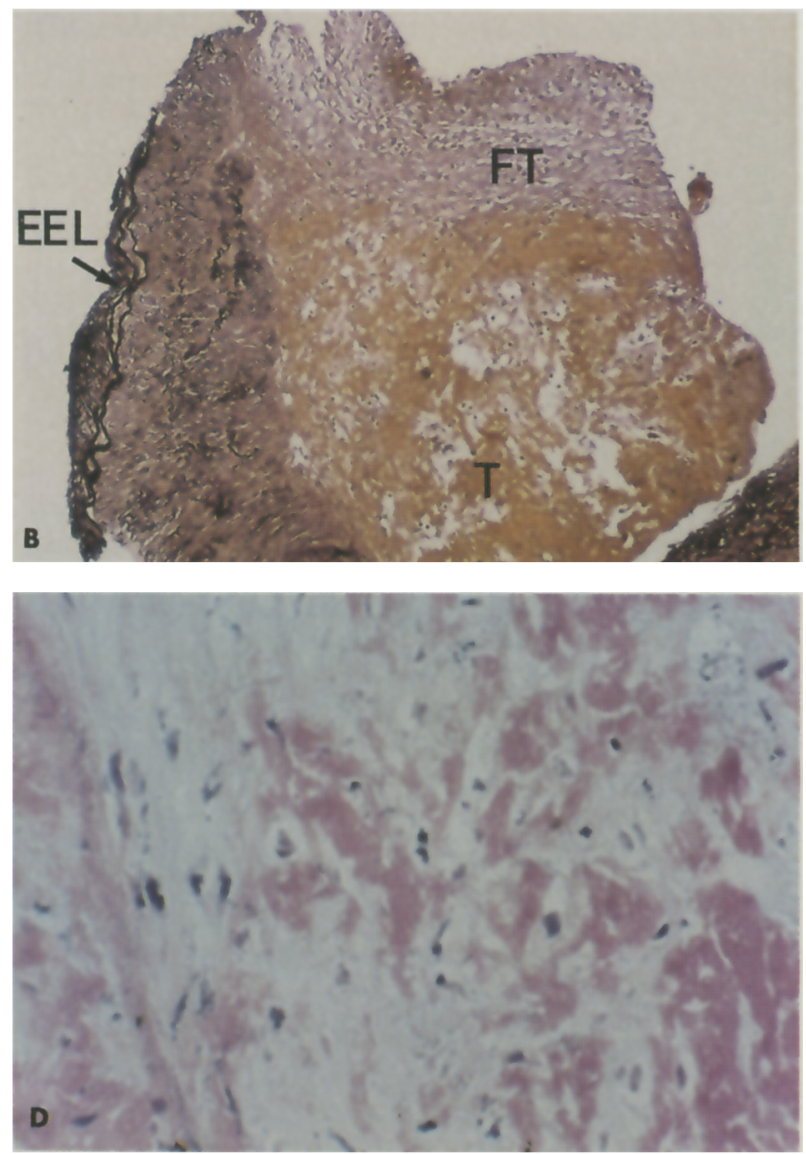

FIGURE 1. Thrombotic material in atherectomy specimens from patients with unstable angina showing different stages of organization. A, early organization 5 days after the onset of angina at rest showing lacunar spaces (arrows) in the thrombotic bulk that are partially covered by endothelial cells (confirmed by positive staining with lectin immunochemistry using Ulex europeus). B, large area of thrombus (T) (yellow) 7 days after the onset of angina at rest in close association to newly formed fibromuscular tissue (FT) and showing partial infiltration by myofibroblasts. Fragments of external elastic lam. ina (EEL) (arrow) and media are evident, indicating that deep vessel resection occurred during atherectomy. $C$ and $D$, advanced thrombus organization by fibromuscular tissue 2 days after the onset of angina at rest. Although virtual incorporation to the vessel wall has taken place, it is possible to identify strands of thrombotic material surrounded by connective tissue (D). A, C and D. hematoxylin-azophloxin; $B$ : Verhoeff-van Giesson (original magnification: $A, \times 60 ; B$ and $C, \times 30 ;$ and D, $\times 125$ - reduced by $37 \%$ ). 
No significant differences were found in the clinical characteristics of both groups, with the exception of a higher prevalence of previous myocardial infarction in the unstable group (13 of 48 [27\%] and 21 of 45 [47\%] in stable and unstable patients, respectively; $p=0.05$ ) (Table I). Several associations between clinical vari-
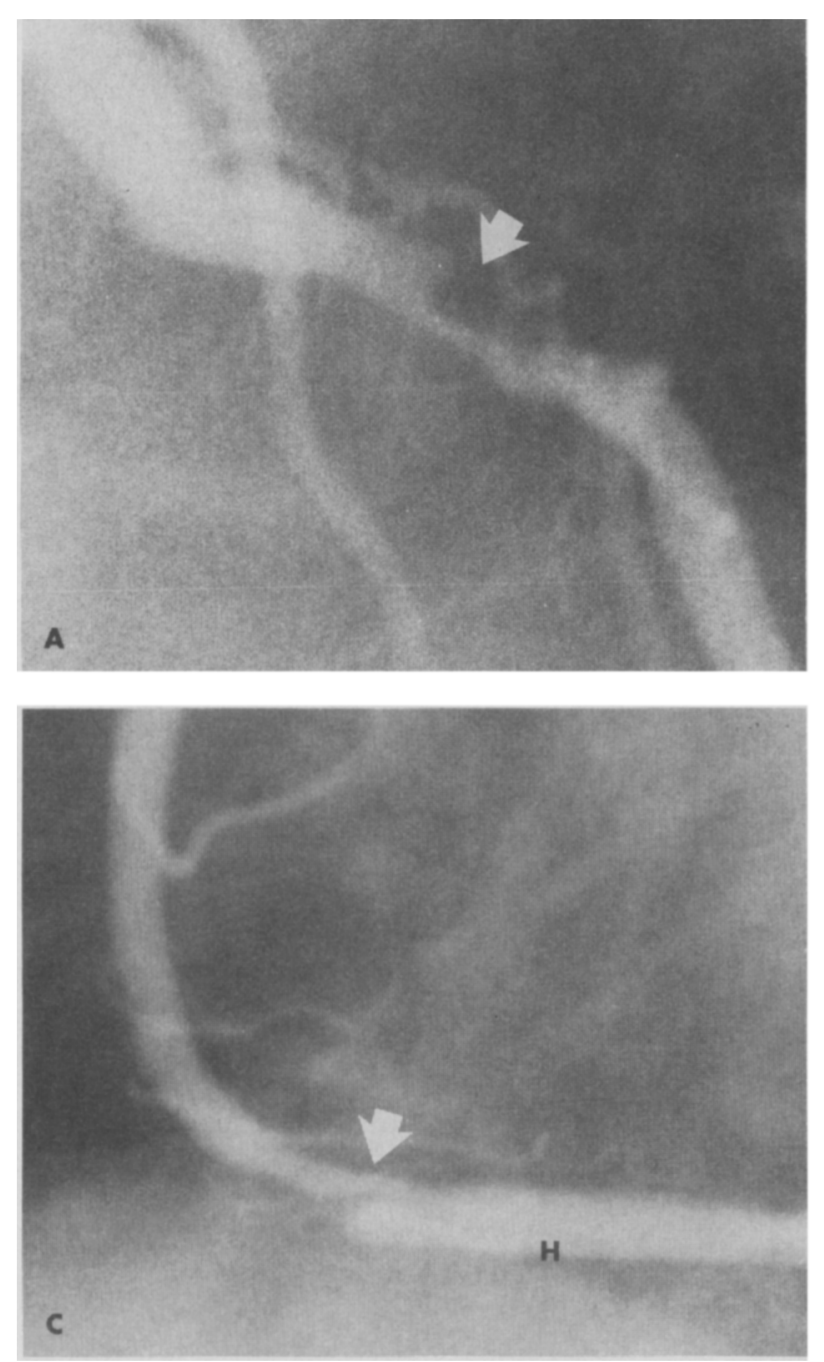

ables were observed in the patient population. The mean age of male patients was significantly lower than that of female patients $(56 \pm 10$ vs $64 \pm 11$ years: $p=0.004$ ). Patients with hypercholesterolemia frequently belonged to families with a history of coronary artery disease (67 vs $13 \%$ in other patients, $p=0.003)$.
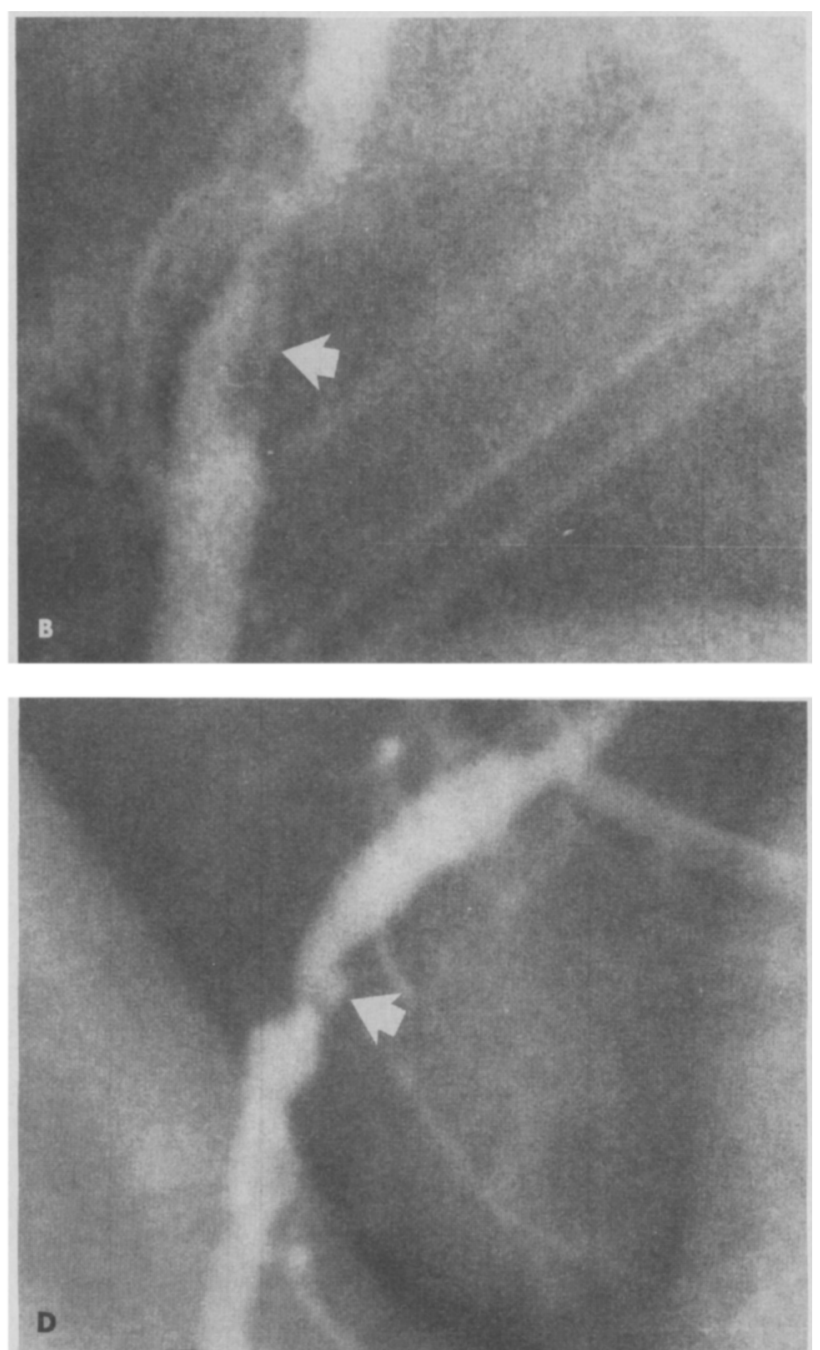

FCURE 2. Complex angiographic mompology in 4 patients with unstable angina and histologic evidence of coronary throm bosis. A to $D$ shows complex eccentric lesions with overhanging edges (arrows).

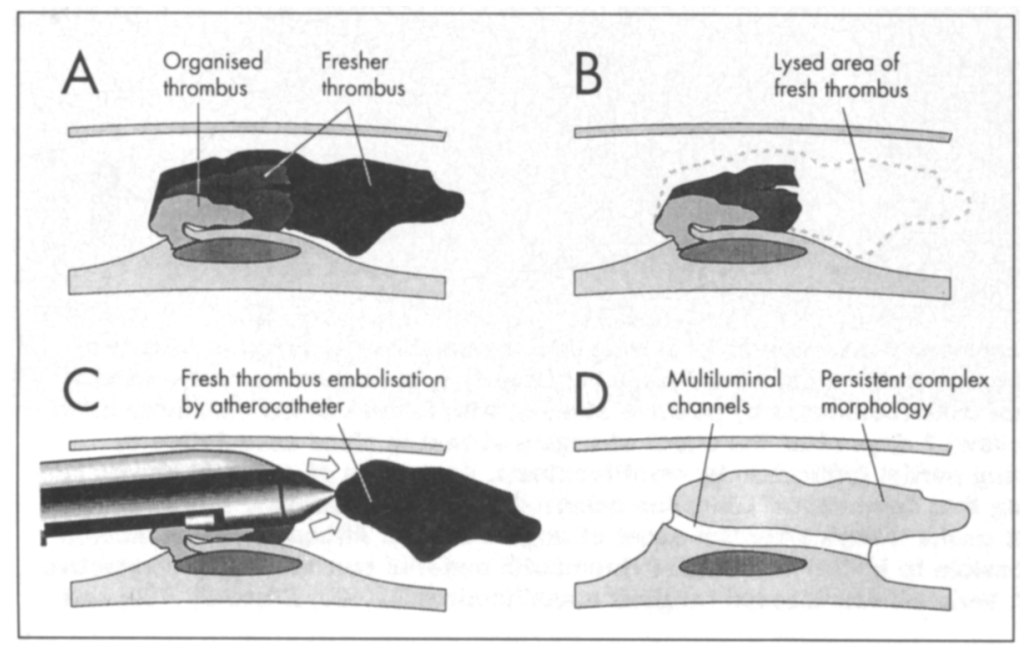

FIGURE 3. Mural thrombosis in unstable angina, and histologic findings in atherectomy specimens. A, episodic thrombus growth has been proposed as a characteristic feature of unstable angina, yielding areas of different degrees of organization. Fresher areas of thrombus may have been missed in athorectomy specimens due to spontanoous lysis and concomitant treatment with intravenous heparin (B), or by dislodgement and embolization of the more labile fraction of thrombus by the atherocatheter (C). In some cases, complex angiographic morphology may have resulted from persisting irregulari ties or multiluminal channels in relation to the recanalization of prior episodes of plaque ulceration (D). 
Twenty-four patients had a previous history of coronary intervention, including 14 balloon angioplasties, 6 stent implantations, 3 atherectomy procedures and 1 excimer laser angioplasty. The mean time interval between

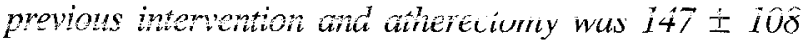
days.

The most striking difference between the syndromes was the presence of foci of thrombus or intraplaque hemorrhage in 10 of 45 (22\%) unstable and only in 1 of $48(2 \%)$ stable patients $(p=0.007)$. Only 1 of these patients had had a previous coronary intervention. All the samples showed some degree of cellular organization (including the presence of endothelial cells covering newly formed channels or capillary vessels present in thrombotic mass originating from the surrounding tissue), the appearance of smooth muscle cells or myofibroblasts, and the presence of thrombotic material embedded in fibrocellular tissue, the latter characteristic suggesting that the masses of fibrin and platelets derived from an episode of thrombosis or plaque hemorrhage were being integrated in the atheromatous plaque (Figure 1, A to D). Thrombus was apposed to fibrous tissue in all cases, without endothelial cells in the interface between both. A lack of relation between the time interval from the onset of angina at rest to atherectomy and the degree of thrombotic organization was evident. Likewise, the relation between angiographic morphology and the presence of thrombus in the retrieved tissue did not reach statistical significance. Complex angiographic morphology was noted in 17 of 45 unstable patients (37\%) (Figure 2). Thrombus or plaque hemorrhage was present in 6 of these patients (35\%) and in 4 of those with non-complex angiographic morphology (14\%) $(p=N S)$.

Calcium deposits were also observed more frequently in patients with unstable (18 of 45 samples, $40 \%$ ) than stable (9 of 48 samples, 19\%) angina $(p=0.042)$. No significant differences were found with regard to the presence of fibrous tissue, cholesterol clefts, necrotic core or clusters of macrophages. In the overall population, complex atheromatous samples (containing dense fibrous tissue, calcium deposits and necrotic debris) were obtained in older patients (58 \pm 10 us $51 \pm 12$ years, $p<0.031$ ). Necrotic debris was observed in 7 of 34 cigarette smokers (21\%) versus 2 of 59 nonsmokers (4\%) $(p=0.019)$. Macrophages were identified in 4 of $15(27 \%)$ and 5 of $78(6 \%)$ samples with and without necrotic debris, respectively ( $p=$ 0.05 ).

Neointimal hyperplasia was observed in 17 of 24 patients (71\%) with previous coronary intervention and in 14 of 69 patients (20\%) with primary lesions $(p=0.0001)$. Neointimal hyperplasia had identical characteristics in patients with previous balloon angioplasty, stenting, atherectomy or laser angioplasty. Particular attention was paid to the 14 patients with primary lesions showing typical neointimal hyperplasia. When compared with other primary lesions, no relation to the type of coronary syndrome was observed: 6 patients had stable and 8 unstable angina pectoris $(p=N S)$. Likewise, no association with sex, coronary artery disease risk factors or previous myocardial in- farction was found. However, the mean age of patients with primary lesions showing neointimal hyperplasia was significantly lower than that of patients with primary lesions and other histologic characteristics $151 \pm$ is vs sy \pm 10 years, $p=0.017$ ).

'l'he retrieval of atheromatous material during directional coronary atherectomy has created new possibilities in the study of coronary syndromes. Although limited by lesion selection and sampling characteristics, ${ }^{8}$ the collection and analysis of the removed tissue has the considerable advantage of allowing the pathologic assessment of coronary artery disease "in-vivo," thus avoiding the selection bias inherent in postmortem studies. To our knowledge, the present work represents the first comparative study of the histopathologic substrate of 2 different coronary syndromes using atherectomy retrieved material.

Primary unstable angina is considered to be an acute thrombotic syndrome ${ }^{2-5}$ occurring predominantly in patients with widespread coronary artery disease. ${ }^{9}$ Coronary thrombosis does not result initially in transmural myocardial necrosis because of incomplete, episodic vessel obstruction, intermittent spontaneous vessel recanalization, or the presence of well-developed collateral anastomoses. ${ }^{3,4}$ Different observations suggest that the associated mural thrombus is very rich in platelet aggregates and has a layered appearance. ${ }^{2}$

In the present study a higher prevalence of mural thrombus and plaque hemorrhage in unstable angina was also observed: thrombus was identified in atherectomy samples obtained from the ischemia-related coronary lesion of $22 \%$ of unstable and in only $2 \%$ of stable patients. This figure is lower than the prevalence of thrombus suspected in angiographic studics ${ }^{3}$ but similar to that reported in a necropsy study of patients with unstable angina. ${ }^{9}$ It is remarkable that no statistical relation between complex angiographic morphology and presence of thrombus in the tissue retrieved could be found, although several explanations can be given for this. The persistence of complex angiographic morphology in the long term has been reported in $57 \%$ of cases by Haft and Al-Zarka. ${ }^{10} \mathrm{~A}$ complex angiographic morphology may also result from multiluminal channels that are frequent in atheromatous plaques of unstable patients ${ }^{11}$ (Figure 3D). Unstable angina may also result from changes in plaque geometry secondary to intraplaque hemorrhage, which may be difficult to differentiate from mural thrombus during the study of isolated fragments of the arterial wall.

An interesting finding is that all samples containing thrombus or intraplaque hemorrhage material showed different degrees of cellular organization that, on the grounds of the time scale of thrombus organization observed in experimental models, ${ }^{12}$ bore no relation to the time interval between the onset of chest pain and atherectomy. This may suggest that the onset of coronary thrombosis or plaque hemorthage had preceded the development of angina at rest by several days or weeks. The retrieved organizing thrombus may thus correspond to either an episode of plaque hemorrhage or to a first episode of subocclusive thrombosis that after episodic growth or rethrombosis led to the development of symp- 
toms $^{2}$ (Figure 3A). The absence of fresh thrombus in these samples could be due to spontaneous lysis and inhibition of further thrombosis by continued systemic heparinization (Figure 3B) or embolization of that labile fraction of thrombus during catheter manipulation (Figure $3 \mathrm{C}$ ).

These observations may have implications for therapeutic and diagnostic approaches in unstable patients. The low prevalence of observed thrombus and the degree of organization or embedded thrombus in the atheromatous plaque may explain the therapeutic failure of thrombolytic agents in primary unstable angina. 13,14 One should clarify whether some of the angioscopic characteristics of coronary thrombus observed in unstable patients, such as the characteristic greyish appearance reported by Mizuno et $\mathrm{al}^{5}$ could be related not only to platelet-rich thrombus, but also to organizing characteristics of thrombus, since it is well known that the macroscopic appearance and color of thrombus shifts progressively toward a pale, whitish color as organization increases. ${ }^{15}$

The cause of the initial event in the development of mural thrombosis, plaque rupture or fissuring, remains controversial. In this study, macrophages, which have been identified in areas of the fibrous cap that are prone to rupture, ${ }^{16}$ were not observed preferentially in unstable plaques but preferentially in plaques with necrotic core. Only fibrous tissue was found in close association with thrombus, an observation that may be relevant to the kind of initiating thrombogenic stimuli. Although no endothelium could be identified in the area covered by thrombus, no firm conclusions can be drawn from this because experimental studies have shown that endothelial cells are rarely observed 3 days after being engulfed by mural thrombosis. ${ }^{12}$

The higher prevalence of calcium deposits in unstable plaques may be related to the frequent existence of severe and widespread coronary artery disease in unstable patients. ${ }^{11}$ A proportional relation between complex atheroma and age was also evident in the overall study population, in agreement with the current knowledge of the sequence of events leading to the progression of coronary artery disease. ${ }^{17}$

Our results also support previous observations in coronary atherectomy specimens showing that neointimal hyperplasia constitutes the pathologic substrate of restenosis after coronary intervention, ${ }^{18}$ irrespective of the revascularization technique used previously. Typical atherosclerotic tissue was also retrieved in a substantial number of restenotic lesions, although this is probably due to the sampling characteristics of the device or in circumstances where restenosis was due to mechanisms other than neointimal hyperplasia. ${ }^{8}$ In accordance with a previous study, ${ }^{19}$ neointimal hyperplasia was also found in a substantial number of primary lesions. We noted that these patients were significantly younger than others with typical primary atherosclerotic lesions, a fact that may have particular relevance since fibromuscular neointimal proliferation has been reported as the pathologic substrate for coronary artery disease in the young, resulting in sudden death. ${ }^{20}$ The ultimate meaning of this observation as to the natural history of atherosclerosis remains unclear. Neointimal hyperplasia represents an unspecific vessel wall response to different kinds of injury that lead to accelerated forms of atherosclerosis. Whether the presence of this type of tissue in primary lesions of young, symptomatic patients is a reflection of less-known factors initiating the atherosclerotic process (e.g., viral endothelial injury, genetical predisposition) remains hypothetical.

Histologic studies based on atherectomy specimens are biased by selective plaque sampling, ${ }^{8}$ although in the present study this limitation was partially overcome by routinely performing multiple cuts in different sectors of the vessel. Case selection may have occurred since only vessels judged suitable for the technique were treated (e.g., coronary atherectomy was performed in only $1 \mathrm{pa}-$ tient with total occlusion). The differentiation between mural thrombosis and foci of plaque hemorrhage is strongly limited by the analysis of isolated fragments of atheroma. Atherectomy was performed in stenoses that were identified on the grounds of clinical, angiographic and electrocardiographic data as ischemia-related stenoses. However, this "culprit lesion" approach may not have been free from a number of confounding factors, including the persistence of complex angiographic morphology from a previous event ${ }^{10}$ (Figure 3D), and the development of myocardial ischemia "at a distance" by a different coronary narrowing.

Despite these limitations, the results of the present study emphasize the use of directional coronary atherectomy as a means of investigation during its therapeutic use. The identification of such features as an increased prevalence of organized thrombus in patients presenting with unstable angina, and of neointimal hyperplasia in primary coronary lesions of younger patients contributes further to our knowledge of the processes that take place in the coronary arteries during the natural history of coronary syndromes.

1. Betriu $A$, Heras $M$, Cohen $M$, Fuster V. Unstable angina: outcome according to clinical presentation. I Am Coll Cardiol 1992;19:1659-1663.

2. Falk $E$. Unstable angina with fatal outcome: dynamic coronary thrombosis leading to infarction and/or sudden death. Circulation 1985;71:699-708.

3. Ambrose JA. Plaque disruption and the acute coronary syndromes of unstable angina and myocardial infarction: if the substrate is similar, why is the clinical presentation different? J Am Coll Cardiol 1992;19:1653-1658.

4. Fuster V, Badimon L, Cohen M, Ambrose JA, Badimon JJ, Chesebro J. Insights into the pathogenesis of acute ischemic syndromes. Circulation 1989;77:1213-1220. 5. Mizuno K, Miyamoto A, Satomura K, Kurita A, Arai T, Sakurada M, Yanagida $\mathrm{S}, \mathrm{Nakamura} \mathrm{H}$. Angioscopic coronary macromorphology in patients with acute coronary disorders. Lancet 1991;337:809-812.

6. Stary HC, Blackenhorn DH, Chandler B, Glagov S, Insull W, Richardson M, Rosenfeld ME, Schaffer SA, Schwartz CJ, Wagner WD, Wissler RW, A definition of the intima of human arteries and of its atherosclerosis-prone regions. Circulation 1992;85:391-405.

7. Ambrose JA, Winters SL, Tern A. Angiographic morphology and the pathogenesis of unstable angina pectoris. J Am Coll Cardiol 1985;5;609-616.

8. Waller BF, Pinkerton CA. "Cutters, scoopers, shavers and scrappers": the importance of atherectomy devices and clinical relevance of tissue removed. $J$ Am Coll Cardiol 1990;15:426-428.

9. Kragel AH, Gertz SD, Roberts WC. Morphologic comparison of frequency and types of acute lesions in the major epicardial coronary arteries in unstable angina pectoris, sudden coronary death and acute myocardial infarction. I Am Coll Cardiol 1991;18:801-808.

10. Haft J, AI-Zarka AM. The origin and fate of complex coronary lesions. Am Heart $J$ 1991;121:1050-1061.

11. Kragel AH, Reddy SC, Wittes JT, Roherts WC. Morphometric analysis of the composition of coronary arterial plaques in isolated unstable angina pectoris with pain at rest. Am J Cardiol 1990;66:562-567.

12. Hand RA, Chandler AB. Atherosclerotic metamorphosis of autologous pul- 
monary thromoemboli in the rabbit. Am J Pathol 1962;40:469-486. 13. Davies MJ. Successful and unsuccessful coronary thrombolysis. Br Heart J $1989 ; 61: 381-384$

14. Vetrovec $\mathrm{GW}$, Leinbach $\mathrm{RC}$, Gold $\mathrm{HK}$, Cowley MJ. Intracoronary thrombolysis in syndromes of unstable ischemia: angiographic and clinical results. Am Heart $J$ 1982; 104:946-952.

15. Pearson TA, Dillman J. Solez, K. Hentinctall RH Monnchnsl characterictic: of organising arterial thrombi: significance in the origin and growth of human atherosclerotic plaques, Lancet 1979;1:7-11.

16. Lendon $C L$, Davies MJ, Born GVR, Richardson PD. Atherosclerotic caps are locally weakened when macruplaye density is incleased. Alherosclerosis 1991; 87:87-90.
17. Stary $\mathrm{HC}$. 'The sequence of cell and matrix changes in atherosclerotic lesions of coronary arteries in the first forty years of life. Eur Heart $J$ 1990;11(suppl E):3-19.

18. Garrat KN, Edwards WD, Kaufmann UP, Vlietstra RE, Holmes DR Jr. Differential histopathology of primary atherosclerotic and restenotic lesions in coronary arteries and saphenous vein bypass grafts: analysis of tissue obtained from 73

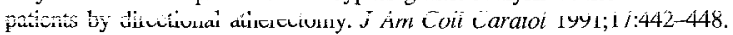

19. Safin RD, Gelbish IS, Eny RE, Schnitt SJ, Schnidt DA, Baim DS. Coronary atherectomy. Clinical, angiographic, and histological findings and observations regarding potential mechanisms. Circulation 1990;82:69-79.

20. Cortado D, Thiene G, Pennelli N. Sudden death as the first manifestation of coronary artery disease in young people ( $\leq 35$ years). Eur Heart $J$ 1988:9:139-144.

\section{Comparison of Patients with Single, Double and Triple Coronary Arterial Spasm}

Noboru Watanabe, MD, Minoru Hongo, MD, Shinichi Okubo, MD, Hiroyoshi Yamada, MD, Takuo Misawa, MD, Jun Kono, MD, Masao Tanaka, MD, Tatsuya Nakatsuka, MD, and Morie Sekiguchi, MD

t is generally accepted that coronary arterial spasm plays an important role in ischemic heart disease. Some investigators described a case report showing spontaneous 3 -vessel coronary vasospasm. ${ }^{1}$ The other pointed out that multivessel coronary vasospasm is not rare. ${ }^{2}$ The purpose of this report is to compare patients with 1-, 2- and 3-vessel coronary arterial spasm without significant organic stenosis and to elucidate the clinical characteristics and risk factors of them.

Thirty-five patients with vasospastic angina $(26$ men and 9 women, mean age 57 years, range 40 to 70 ) were included in the present study. All patients were referred to our hospital for chest pain and suggested to have angina pectoris from their history. Coronary vasospasm and ischemic electrocardiographic changes or chest pain were demonstrated during coronary angiography

From the First Department of Internal Medicine, Shinshu University School of Medicine, 3-1-1 Asahi, Matsumoto 390, Japan. Manuscript received September 28, 1992; revised manuscript received January 4 , 1993, and accepted January 5. in these patients. However, no significant fixed stenosis was found after administration of nitroglycerin to the patients. According to 3 main coronary arteries with vasospasm on coronary angiography, the patients were classified into 1 of the following 3 groups: group 1 consisted of 19 patients (54\%) showing coronary vasospasm of only 1 vessel; group 2 consisted of $7 \mathrm{pa}$ tients (20\%) with coronary vasospasm of 2 vessels; group 3 consisted of 9 patients (26\%) with coronary vasospasm of 3 vessels. Each patient in the fasting state underwent coronary angiographic examination by the Judkins technique. Temporary ventricular pacing was ready to start at a rate of 40 beats $/$ min. During the studies, arterial blood pressure and 12-lead electrocardiogram were continuously monitored. For the provocation test for the coronary vasospasm, intracoronary injection of acetylcholine chloride was performed according to the method by Yasue et al..$^{3}$ Acetylcholine dissolved in warmed $0.9 \%$ saline solution was injected in incremental doses of 20,50,80 and $100 \mu \mathrm{g}$ into the left

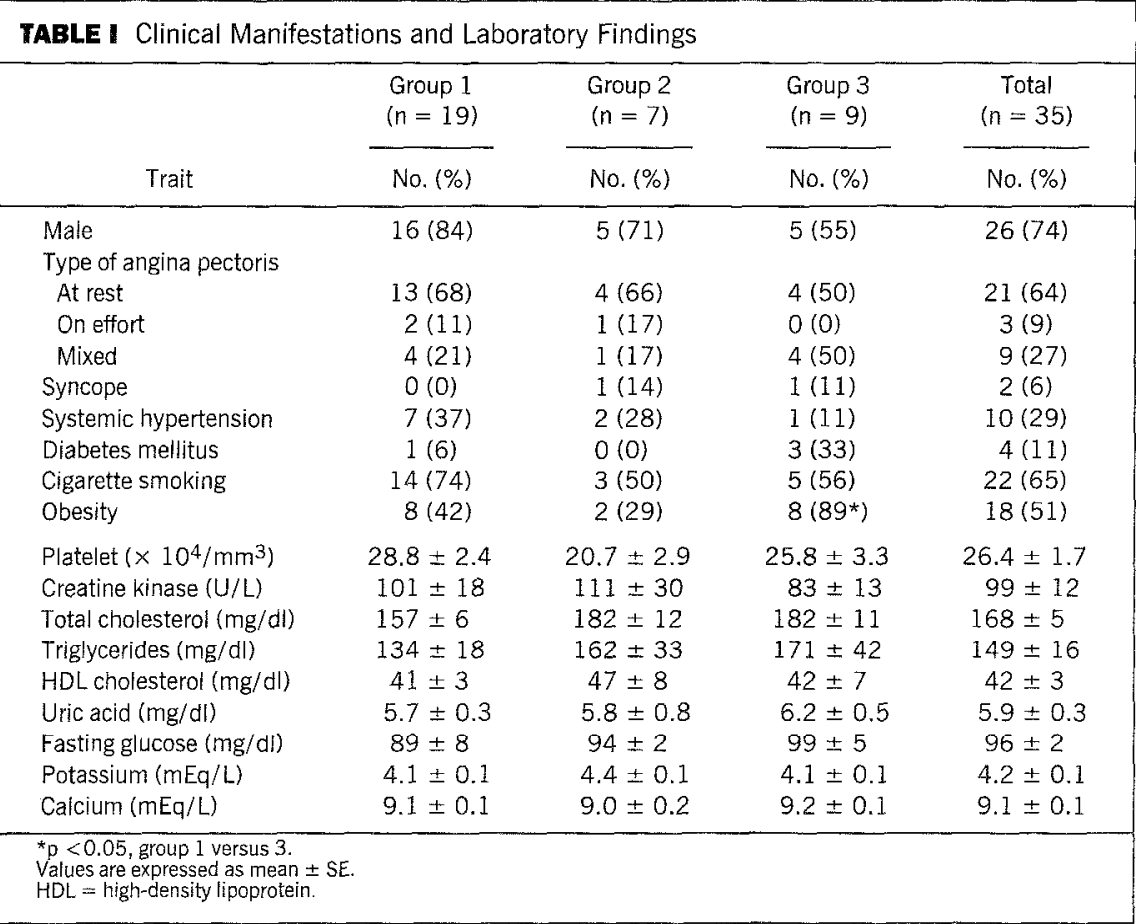

